\title{
Spirometric Indices in Type 2 Diabetes Mellitus Patients in a Nigerian Tertiary Institution
}

\author{
Adekunle O. Adeoti, Taiwo H. Raimi, Joseph O. Fadare, and Raphael Ibidapo
}

\section{ABSTRACT}

\begin{abstract}
Background: Diabetes mellitus is a non-communicable disease of global health importance. It is a metabolic disorder caused by increased levels of blood glucose over a prolonged period of time. Type 2 diabetes mellitus (T2DM) is usually associated with obesity and insulin resistance. Several studies have also revealed that diabetes mellitus hampers pulmonary functions. This study was aimed at estimating the spirometric indices in type 2 diabetes mellitus patients.
\end{abstract}

Methods: A cross-sectional study of T2DM patients and apparently healthy control attending the medical outpatient clinic in a tertiary institution in south western Nigeria.

Results: A total of 146 participants with 73 patients with T2DM and 73 control groups. There were no significant differences in the age, body mass index, and gender distribution of the diabetics and control. However, patients with diabetes had higher SBP $(\mathbf{1 3 3 . 2} \pm \mathbf{2 0 . 1 7} \mathbf{m m H g}$ vs 111.6 $\pm 6.5 \mathrm{mmHg} p<0.0001)$, and DBP $(78.4 \pm 11.8 \mathrm{mmHg}$ vs $73.7 \pm 6.3 \mathrm{mmHg}$, $p=0.003)$ when compared to the control. The mean FEV $(1.98 \pm 0.5$ vs $2.09 \pm 1.2, p=0.033), F V C(2.35 \pm 0.6$ vs $2.53 \pm 1.3, p=0.045)$ and FEV/FVC ratio $(83.61 \pm 7.2$ vs $81.14 \pm 10.7, p=0.029)$ were significantly lower in diabetic patients when compared to matched controls. There was no significant difference in the PEF and FEF of both groups.

Conclusion: Type 2 diabetes mellitus patients had significant decrease in their spirometric indices, hence pulmonary function should be included in the periodic comprehensive diabetic check for holistic management.

Keywords: Pulmonary function, Spirometric indices, Diabetes Mellitus, Non-communicable diseases.

\section{INTRODUCTION}

Diabetes mellitus is a metabolic non-communicable disease, one of the most serious public health challenges worldwide [1], [2]. Globally, it was estimated that 451 million people developed diabetes mellitus in 2017, and this is expected to increase to 693 million by 2045 [3]. Diabetes mellitus is one of the non-communicable diseases (NCD) with global rising burden and it is associated with various microvascular and macrovascular complications which contribute to increased morbidity and mortality [4].

Type 2 Diabetes Mellitus (T2DM) comprises $90 \%$ of the global burden of diabetes mellitus, interfacing the increase burden of other NCD like obesity, hyperlipidemia, and systemic hypertension as well as communicable diseases like tuberculosis [5]. There is a global rise in the incidence of T2DM with $80 \%$ of people with DM living in low- and middle-income countries and an observed increase in the burden in the African population [2], [6]. Nigeria has the highest burden of diabetes mellitus in Africa, with every 1 in 17 adults having this disease [7], [8]. The multi-systemic effects of DM and the consequent microvascular damage affect virtually every organ by the glycation of connective Nigeria.
Submitted : May 24, 2020

Published : May 07, 2021

ISSN: $2593-8339$

DOI: $10.24018 /$ ejmed.2021.3.3.293

\section{A. O. Adeoti*}

Department of Medicine, Ekiti State University, Ado-Ekiti, Nigeria.

(e-mail: kadeoti2002@yahoo.com)

T. H. Raimi

Department of Medicine, Ekiti State University, Ado-Ekiti, Nigeria.

(e-mail: taiwo.raimi ${ }^{\circledR}$ eksu.edu.ng)

J. O. Fadare

Department of Medicine, Ekiti State University, Ado-Ekiti, Nigeria.

(e-mail: jofadare@gmail.com)

R. Ibidapo

Department of Medicine, Ekiti State University, Ado-Ekiti, Nigeria.

(e-mail: raphibidapo@gmail.com)

*Corresponding Author

tissue and collagen in most tissues [9]-[12]. The abundant microvascular circulation and connective tissue in the lungs raises the possibility of lung affectation. The histopathologic evidence of lung involvement in subjects with DM has included thickened alveolar epithelial and pulmonary capillary basal laminae, the latter suggestive of existing pulmonary microangiopathy [13]. Studies have shown impaired lung function among patients with diabetes mellitus [14]-[17]. On the contrary, some investigators reported no decline in lung function among patients [18].

Despite these conflicting reports regarding diabetes mellitus and lung function, few studies have been conducted on this subject in Nigeria and none in our center. Thus, this study was conducted to assess the spirometric indices and their determinants in patients with type 2 diabetes mellitus attending the medical outpatient department of Ekiti State University Teaching Hospital (EKSUTH), Ado-Ekiti, 


\section{METHODS}

\section{A. Study Setting}

This study was conducted at the medical outpatients' clinic of the Ekiti State University Teaching Hospital (EKSUTH), Ado-Ekiti, Nigeria. The hospital is a tertiary facility that serves both general and specialized healthcare needs of the inhabitants of Ekiti State and border communities of neighbouring states.

\section{B. Study Design and Data Collection}

A cross-sectional analytic study among 73 diabetic patients and 73 matched controls. The subjects who participated gave both verbal and written informed consent. The anthropometric measurement, spirometric indices, smoking history and blood pressures of all participants were measured. Biochemical investigations such as fasting plasma glucose and haemoglobin A1C (for patients with diabetes mellitus only) were determined.

\section{Sample Size Considerations}

The sample size of the study was 146 adult patients comprising 73 diabetes mellitus and 73 controlled group. This was determined using the select statistical services software formula for sample size in a comparative study and setting the study power at $80 \%$ [19]. To derive our sample size, we used prevalence data from a previously published local study on prevalence of abnormal spirometric indices in T2DM in Nigeria [20].

\section{Anthropometry}

Participants' weight was measured with a digital weighing scale (OMRON 511, OMRON healthcare Co., Ltd. Japan) to the nearest $0.1 \mathrm{~kg}$. Height was determined with a stadiometer to the nearest $0.1 \mathrm{~m}$ while standing without shoes, head gear or cap. Body mass index was taken as weight $(\mathrm{kg}) / \mathrm{height}$ $(\mathrm{m})^{2}$. Body mass index was defined according to the WHO classification: $<18.5 \mathrm{~kg} / \mathrm{m}^{2}$, underweight; 18.5 to $24.9 \mathrm{~kg} / \mathrm{m}^{2}$, normal; 25.0 to $29.9 \mathrm{~kg} / \mathrm{m}^{2}$, overweight; $>30 \mathrm{~kg} / \mathrm{m}^{2}$, obese. [21].

\section{E. Spirometric Indices}

The spirometric indices (FEV1, FVC, FEV\%, PEFR, and FEF25-75\%) were measured using spirometer (spirolab ${ }^{\circledR}$ ) in accordance with recommendations of the American Thoracic Society (ATS). The apparatus was calibrated for each procedure and three maneuvers were performed per subject. The maximum value of three trials was used for analysis. The American Thoracic Society/European Respiratory Society (ATS/ERS) guideline was used to categorize spirometry values into obstructive, restrictive, and mixed patterns. The percentage predicted value was calculated dividing observed value by predicted value and multiplying by 100 and this value was automatically inputted and calculated by the spirometer. [22]

\section{F. Blood Pressure Measurement}

The blood pressure was measured on the left upper arm with the participants in sitting position. Accussons $₫$ mercury sphygmomanometer attached to appropriate cuff sizes was used. The first and fifth Koroktoff sounds were taken as the systolic and diastolic blood pressures respectively. Systemic hypertension was defined as persistent elevation of blood pressure $\geq 140 / 90 \mathrm{mmHg}$. [23]

\section{G. Biochemical Analysis}

After an overnight fast, plasma venous blood was obtained aseptically into fluoride oxalate bottle and plasma glucose was analysed by the glucose oxidase method. Glycosylated haemoglobin was analyzed on capillary blood using the Clover HbA1c analyser (Infopia Co Ltd., Korea) which utilizes a fully automated boronate affinity assay.

\section{H. Statistical Analysis}

Data were coded, entered, cleaned, and analyzed using Statistical Package for Social Science (SPSS) version 22. Descriptive statistics and independent samples t-test were conducted in the data analysis and interpretation. Categorical variables were represented as proportions and compared using chi-square while continuous variables were represented as mean \pm standard deviation and compared using t-test.

\section{Ethical Consideration}

Approval was obtained from the Ethical and Research committee of Ekiti State University Teaching Hospital, AdoEkiti. Verbal and written informed consent were also obtained from all participants and confidentiality was ensured.

\section{RESULTS}

In this study, 73 patients with DM and 73 matched controls were recruited. There is female preponderance in both the DM and control groups. The mean age of the diabetic patients and the matched controls were $69.9 \pm 9.8$ and $59.2 \pm 12.8$ years respectively with no significant statistical difference $(\mathrm{p}=0.14)$.

\begin{tabular}{|c|c|c|}
\hline Variables & $\begin{array}{l}\text { T2DM } \\
\mathrm{N}(\%)\end{array}$ & $\begin{array}{c}\text { Control } \\
\mathrm{N}(\%)\end{array}$ \\
\hline \multicolumn{3}{|l|}{ Gender } \\
\hline Male & $23(31.5)$ & $25(34.2)$ \\
\hline Female & $50(68.5)$ & $48(65.8)$ \\
\hline \multicolumn{3}{|c|}{$\begin{array}{l}\text { Age (years) } 69.9 \pm .859 .2 \pm 12.8 \\
(p=0.14)\end{array}$} \\
\hline Below 40 & $1(1.4)$ & $5(6.8)$ \\
\hline $40-60$ & $32(43.8)$ & $39(53.4)$ \\
\hline Above 60 & $40(54.8)$ & $29(39.7)$ \\
\hline \multicolumn{3}{|l|}{ Smoking history } \\
\hline Ex-smokers & $13(17.8)$ & $6(8.2)$ \\
\hline Never & $60(82.2)$ & $67(91.8)$ \\
\hline
\end{tabular}

As presented in Table I, there was no significant difference in the smoking history of both groups. Majority of the subjects with diabetes mellitus $(52.3 \%)$ were diagnosed between the period of less than 5 years while $3.4 \%$ were diagnosed more than 10 years ago.

Table II shows that there was no significant difference in the anthropometric profile of the subjects. However, the results also indicated that T2DM patients had a significantly higher systolic $(\mathrm{p}<0.001)$ and diastolic $(\mathrm{p}=0.003)$ blood pressure when compared to that of the control.

The spirometric indices as presented in Table II showed significant reduction in forced expiratory volume $(\mathrm{p}=0.033)$, forced vital capacity $(\mathrm{p}=0.045)$ and forced expiratory ratio ( $p=0.029$ ) compared to the control group. However, there was no significant difference in peak expiratory flow rate and the 
forced expiratory flow rate of the diabetic patients and their matched controls. The pattern of lung function amongst diabetic and non-diabetic patients was significantly different $(\mathrm{p}=0.0238)$.

TABLE II: BIOCHEMICAL, ANTHROPOMETRIC AND SPIROMETRIC INDICES

\begin{tabular}{lccc}
\hline \multicolumn{1}{c}{ Variables } & $\begin{array}{c}\text { Diabetic } \\
(\text { mean } \pm \mathrm{sd})\end{array}$ & $\begin{array}{c}\text { Non-diabetics } \\
(\mathrm{mean} \pm \mathrm{sd})\end{array}$ & P-value \\
\hline $\begin{array}{l}\text { Biochemical and Clinical } \\
\text { profile }\end{array}$ & & & \\
SBP (mmHg) & $133.2 \pm 20.17$ & $111.6 \pm 6.5$ & $<0.0001^{* * *}$ \\
DBP (mmHg) & $78.4 \pm 11.8$ & $73.7 \pm 6.3$ & $0.0033^{* *}$ \\
Anthropometric profile & & & \\
Height (m) & $74.2 \pm 17.1$ & $74.8 \pm 23.6$ & 0.859 \\
Weight (kg) & $160.1 \pm 13.2$ & $158.4 \pm 20.1$ & 0.547 \\
BMI $\left(k g / m^{2}\right)$ & & & \\
< 18.51 & $1(1.4)$ & $1(1.4)$ & 0.96 \\
18.5 - 24.9 & $22(30.1)$ & $27(36.9)$ & \\
25-29.9 & $26(35.6)$ & $28(38.4)$ & \\
$>$ 30 & $23(31.5)$ & $16(21.9)$ & \\
Pulmonary function tests & & & \\
FEV1 (L) & $1.98 \pm 0.5$ & $2.09 \pm 1.2$ & $0.033^{* *}$ \\
FVC (L) & $2.35 \pm 0.6$ & $2.53 \pm 1.3$ & $0.045^{* *}$ \\
FEV1/FVC (\%) & $83.61 \pm 7.2$ & $81.14 \pm 10.7$ & $0.029^{* *}$ \\
PEF (L) & $4.92 \pm 1.8$ & $4.88 \pm 2.1$ & 0.65 \\
FEF $25-75$ (L) & $4.64 \pm 0.5$ & $4.54 \pm 0.5$ & 0.965 \\
\hline
\end{tabular}

Keys: BMI, body mass index; DBP, diastolic blood pressure; SBP, systolic blood pressure; FPG, fasting plasma glucose; HbA1c, glycosylated haemoglobin.

Significant p-values were asterisk $(* *)$.

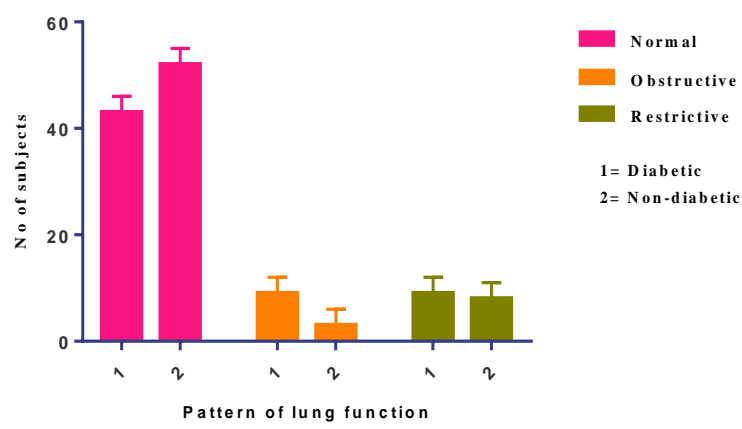

Fig. 1. Pattern of lung function amongst diabetic and non-diabetic patients.

TABLE III: Potential PREDICTORS OF LUNG FunCTION IN DiABETIC PATIENTS

\begin{tabular}{|c|c|c|c|c|}
\hline \multirow[b]{2}{*}{ Variables } & \multicolumn{2}{|c|}{ Lung function } & \multirow[b]{2}{*}{ OR $(95 \% \mathrm{Cl})$} & \multirow[b]{2}{*}{$\mathrm{p}$-value } \\
\hline & $\begin{array}{l}\text { Normal } \\
(\mathrm{n} \%)\end{array}$ & $\begin{array}{c}\text { Abnormal } \\
\text { (n\%) }\end{array}$ & & \\
\hline \multicolumn{5}{|l|}{ Sex } \\
\hline Male & 17 & 6 & 1 & 0.159 \\
\hline Female & 35 & 14 & $6.9(0.4-102.2)$ & \\
\hline \multicolumn{5}{|l|}{ Age } \\
\hline Below 40 & 1 & 1 & 1 & 0.508 \\
\hline $40-60$ & 24 & 8 & 0.000 & 0.100 \\
\hline Above 60 & 27 & 11 & $3.2(0.46-22.0)$ & 0.245 \\
\hline \multicolumn{5}{|l|}{$\begin{array}{l}\text { Duration of } \\
\text { DM }\end{array}$} \\
\hline Below 1 year & 3 & 0 & 1 & 0.662 \\
\hline $1-5$ years & 18 & 11 & 0.000 & 0.100 \\
\hline $5-10$ years & 19 & 6 & 0.000 & 0.999 \\
\hline $\begin{array}{l}\text { Above } 10 \\
\text { years }\end{array}$ & 5 & 0 & 0.000 & 0.999 \\
\hline $\begin{array}{l}H T N \\
\text { Yes } \\
\text { No }\end{array}$ & $\begin{array}{l}33 \\
18\end{array}$ & $\begin{array}{c}13 \\
6\end{array}$ & $11.1(0.57-216.1)$ & 0.111 \\
\hline \multicolumn{5}{|l|}{$H b A 1 c$} \\
\hline 4-5.6 & 1 & 1 & 1 & 0.379 \\
\hline $5.7-6.4$ & 5 & 3 & $4.9(0.22-111.9)$ & 0.319 \\
\hline Above 6.4 & 27 & 6 & $4.6(0.35-60.6)$ & 0.244 \\
\hline
\end{tabular}

Fig. 1 shows the majority of both diabetics and control groups had normal lung functions. However, the diabetic group had the higher proportion of both the obstructive and restrictive lung pattern when compared to the control. In Table III, there is no significant association between potential predictors of lung function (age, sex, hypertension, and duration of diabetes) and the abnormal lung function amongst the subjects with diabetes mellitus.

\section{DISCUSSION}

In this study, there was a reduction in the spirometric indices among T2DM compared to the controls, however there was no significant association in the potential predictors. The profile of the study participants revealed that T2DM patients were more prone to high blood pressure. The SDP and DBP of the subjects with T2DM were significantly higher than that of the control subjects. High blood pressure is a common condition in diabetes mellitus affecting 20-60\% of diabetic patients depending on their body mass index, ethnicity, and age [24]. Studies have shown that individuals with diabetes mellitus are at a much greater risk for developing systemic hypertension than non-diabetic patients which could explained by the presence of comorbidities like hyperlipidemia, obesity and sedentary lifestyle which are major risks for both comorbidities [25], [26].

$\mathrm{HbA} 1 \mathrm{c}$ is a predictor of cardiovascular disease in diabetes mellitus, and it is vital for monitoring of glycemic control over a period of three months [27], [28]. In a similar study, elevated HbA1c was associated with deranged spirometric indices and loss of pulmonary function. [27] In our study, an elevation in the HbA1c in the DM group was observed which is an indicator of the glycemic control and also could explain the reduction in spirometric indices of our study participants in relation to the control group.

In a study of lung function in T2DM in Nigeria, higher proportion abnormal lung function which reported. Likewise, similar findings were the reports from other countries such as Japanese China, France and India where abnormal pulmonary function was seen in diabetes mellitus patients [29]-[32]. These abnormal lung volumes in T2DM were related to the extent of glycemic control. Furthermore, histological distortion in the lungs of T2DM are recognized as collagen deposit, and due to the neuropathies resulting in restrictive pattern of lung function [29].

Reports of predominant restrictive over the obstructive, and mixed obstructive-restrictive lung impairments were found among patients with diabetes mellitus in several of the studies including ours [33]-[37]. In a Nigerian study, 67\% of diabetes mellitus patients had impaired lung function which was mainly restrictive pattern, similar to the findings in this study [20]. Although the proportion of the abnormal lung function was higher in previous study which could the different environmental predisposition to lung diseases like air pollution. A similar study in India, Aparna et al., reported greater increase in FEV1/FVC ratio, in keeping with restrictive pattern, among patients with diabetes mellitus [35]. Impairment in lung function of patients with diabetes mellitus is believed to be the consequence of biochemical alterations in the connective tissue constituents of the lung, particularly collagen and elastin, as well as microangiopathy due to the non-enzymatic glycosylation of proteins induced by chronic hyperglycemia [9], [15], [38], [39]. 
In contrast, Sreeja et al., and Keerthi et al., reported obstructive lung impairment characterized by reduced FEV1/FVC ratio [36], [40], [41]. Albeit the FEV1/FVC\% is a more sensitive indicator of airway obstruction than $\mathrm{FVC}$ or FEV1 alone. The decrease in FEV1/FVC\% in diabetes mellitus subjects may be related with the poor mechanical properties of the lung, like lung compliance and elastic recoil of lungs. Loss of elastic recoil leads to dynamic collapse of small airways during expiration [40]. Consistent with these observations, some authors demonstrated reduction in alveolar gas exchange among patients with T2DM [34]. Furthermore, insulin resistance which is typical of T2DM is also associated with decline in pulmonary function [16].

\section{CONCLUSION}

The lungs are prime targets for diabetes mellitus as pulmonary dysfunction may be one of the earliest and early measurable derangements in T2DM patients. Type 2 Diabetes Mellitus poses an underlying reduction in pulmonary functions alongside other known complications. It is advisable therefore, that diabetic mellitus patients should have periodic spirometry tests to assess the severity of lung function impairment.

\section{REFERENCES}

[1] A. M. Ahmed. History of diabetes mellitus. Saudi Med J, vol. 23, no. 4, pp. 373-378. 2002.

[2] H. W. Baynest. Classification, Pathophysiology, Diagnosis and Management of Diabetes Mellitus. Journal of Diabetes \& Metabolism, vol. 06, no., pp. 2015.

[3] N. H. Cho, J. E. Shaw, S. Karuranga, Y. Huang, J. D. da Rocha Fernandes, A. W. Ohlrogge, B. Malanda. IDF Diabetes Atlas: Global estimates of diabetes prevalence for 2017 and projections for 2045. Diabetes Res Clin Pract, vol. 138, no., pp. 271-281. 2018.

[4] D. Pitocco, L. Fuso, E. G. Conte, F. Zaccardi, C. Condoluci, G. Scavone, R. A. Incalzi, G. Ghirlanda. The diabetic lung--a new target organ? Rev Diabet Stud, vol. 9, no. 1, pp. 23-35. 2012.

[5] W.H.O. Diabetes Fact sheet N312. Geneva: World Health Organization; 2018.

[6] DMICC. Genetic basis of type 1 and type2 diabetes, obesity, and their complications.: DMICC; 2014.

[7] R. N. Oputa, S. Chinenye. Diabetes in Nigeria - a translational medicine approach. African Journal of Diabetes Medicine, vol. 23, no. 1, pp. 7-11. 2015.

[8] A. E. Uloko, B. M. Musa, M. A. Ramalan, I. D. Gezawa, F. H. Puepet, A. T. Uloko, M. M. Borodo, K. B. Sada. Prevalence and Risk Factors for Diabetes Mellitus in Nigeria: A Systematic Review and MetaAnalysis. Diabetes Ther, vol. 9, no. 3, pp. 1307-1316. 2018.

[9] S. Ljubic, Z. Metelko, N. Car, G. Roglic, Z. Drazic. Reduction of diffusion capacity for carbon monoxide in diabetic patients. Chest, vol. 114, no. 4, pp. 1033-1035. 1998.

[10] E. Ofoegbu, S. Chinenye. National Clinical Practice Guidelines for Diabetes Management in Nigeria. Diabetes Association of Nigeria (DAN), vol., no., pp. 2013.

[11] V. P. Singh, A. Bali, N. Singh, A. S. Jaggi. Advanced glycation end products and diabetic complications. Korean J Physiol Pharmacol, vol. 18, no. 1, pp. 1-14. 2014.

[12] United Nations General Assembly. Declaration 61/295 on the Rights of Indigenous Peoples. New york: United nations; 2008.

[13] M. Sandler. Is the lung a 'target organ' in diabetes mellitus? Arch Intern Med, vol. 150, no. 7, pp. 1385-1388. 1990.

[14] J. Giovannelli, P. Trouiller, S. Hulo, N. Cherot-Kornobis, A. Ciuchete, J. L. Edme, R. Matran, P. Amouyel, A. Meirhaeghe, L. Dauchet. Lowgrade systemic inflammation: a partial mediator of the relationship between diabetes and lung function. Ann Epidemiol, vol. 28, no. 1, pp. 26-32. 2018.

[15] O. L. Klein, J. A. Krishnan, S. Glick, L. J. Smith. Systematic review of the association between lung function and Type 2 diabetes mellitus. Diabet Med, vol. 27, no. 9, pp. 977-987. 2010.
[16] G. Sagun, C. Gedik, E. Ekiz, E. Karagoz, M. Takir, A. Oguz. The relation between insulin resistance and lung function: a cross sectional study. BMC Pulm Med, vol. 15, no., pp. 139. 2015.

[17] I. Vanidassane, R. Malik, N. Jain. Study of Pulmonary function tests in Type 2 Diabetes Mellitus and their correlation with glycemic control and systemic inflammation. Adv Respir Med, vol., no., pp. 2018.

[18] C. A. Benbassat, E. Stern, M. Kramer, J. Lebzelter, I. Blum, G. Fink. Pulmonary function in patients with diabetes mellitus. Am J Med Sci, vol. 322, no. 3, pp. 127-132. 2001

[19] https://select-statistics.co.uk/contact-us/. vol., no., pp

[20] O. Adeyeye, A. Ogbera. Correlates of Abnormal Lung Functions in Type 2 Diabetes in Lagos, Nigeria. CHEST, vol. 146, no. 4, pp. 806A. 2014.

[21] W.H.O. Obesity: preventing and managing the global epidemic.Report of a WHO consultation. Geneva: World Health Organization; 2000.

[22] M. R. Miller, J. Hankinson, V. Brusasco, F. Burgos, R. Casaburi, A. Coates, R. Crapo, P. Enright, C. P. van der Grinten, P. Gustafsson, R. Jensen, D. C. Johnson, N. MacIntyre, R. McKay, D. Navajas, O. F. Pedersen, R. Pellegrino, G. Viegi, J. Wanger, A. E. T. Force. Standardisation of spirometry. Eur Respir J, vol. 26, no. 2, pp. 319-338. 2005.

[23] A. V. Chobanian, G. L. Bakris, H. R. Black, W. C. Cushman, L. A. Green, J. L. Izzo, Jr., D. W. Jones, B. J. Materson, S. Oparil, J. T. Wright, Jr., E. J. Roccella, D. E. Joint National Committee on Prevention, L. Treatment of High Blood Pressure. National Heart, I. Blood, C. National High Blood Pressure Education Program Coordinating. Seventh report of the Joint National Committee on Prevention, Detection, Evaluation, and Treatment of High Blood Pressure. Hypertension, vol. 42, no. 6, pp. 1206-1252. 2003.

[24] Z. Anwer, R. K. Sharma, V. K. Garg, N. Kumar, A. Kumari. Hypertension management in diabetic patients. Eur Rev Med Pharmacol Sci, vol. 15, no. 11, pp. 1256-1263. 2011.

[25] C. Arauz-Pacheco, M. A. Parrott, P. Raskin. The treatment of hypertension in adult patients with diabetes. Diabetes Care, vol. 25, no. 1, pp. 134-147. 2002.

[26] G. L. Bakris, M. Williams, L. Dworkin, W. J. Elliott, M. Epstein, R. Toto, K. Tuttle, J. Douglas, W. Hsueh, J. Sowers. Preserving renal function in adults with hypertension and diabetes: a consensus approach. National Kidney Foundation Hypertension and Diabetes Executive Committees Working Group. Am J Kidney Dis, vol. 36, no. 3, pp. 646-661. 2000.

[27] S. F. Akram, E. Asharaf, S. H. Masood, S. M. M. Ali. Association of Pulmonary Functions and HbA1c in Diabetics. PJMHS, vol. 7, no. 2, pp. 306 -309. 2013.

[28] J. Zheng, J. Cheng, T. Wang, Q. Zhang, X. Xiao. Does HbA1c Level Have Clinical Implications in Diabetic Patients Undergoing Coronary Artery Bypass Grafting? A Systematic Review and Meta-Analysis. Int J Endocrinol, vol. 2017, no., pp. 1537213. 2017.

[29] W. A. Davis, M. Knuiman, P. Kendall, V. Grange, T. M. Davis, S Fremantle Diabetes. Glycemic exposure is associated with reduced pulmonary function in type 2 diabetes: the Fremantle Diabetes Study. Diabetes Care, vol. 27, no. 3, pp. 752-757. 2004.

[30] M. D. Goldman. Lung dysfunction in diabetes. Diabetes Care, vol. 26, no. 6, pp. 1915-1918. 2003.

[31] M. Irfan, A. Jabbar, A. S. Haque, S. Awan, S. F. Hussain. Pulmonary functions in patients with diabetes mellitus. Lung India, vol. 28, no. 2, pp. 89-92. 2011.

[32] S. A. Meo, A. M. Al-Drees, M. Arif, K. Al-Rubean. Lung function in type 2 Saudi diabetic patients. Saudi Med J, vol. 27, no. 3, pp. 338-343. 2006.

[33] N. Agarwal, S. Kaur. Pulmonary function tests in type 2 diabetes mellitus. Archives of Medicine and Health Sciences, vol. 4, no. 1, pp. 2016.

[34] S. M. S. Anandhalakshmi, Ganeshkumar, P, Ramachandran, C. Alveolar Gas Exchange and Pulmonary Functions in Patients with Type II Diabetes Mellitus. J Clin Diagn Res, vol. 7, no. 9, pp. 1874 1877. 2013.

[35] Aparna. Pulmonary function tests in type 2 diabetics and non-diabetic people -a comparative study. J Clin Diagn Res, vol. 7, no. 8, pp. 16061608. 2013.

[36] H. Huang, Q. Guo, L. Li, S. Lin, Y. Lin, X. Gong, J. Yao, J. Liang, L. Lin, J. Wen, G. Chen. Effect of type 2 diabetes mellitus on pulmonary function. Exp Clin Endocrinol Diabetes, vol. 122, no. 6, pp. 322-326. 2014.

[37] H. Y. Kim, T. S. Sohn, H. Seok, C. D. Yeo, Y. S. Kim, J. Y. Song, Y. B. Lee, D. H. Lee, J. I. Lee, T. K. Lee, S. C. Jeong, M. Hong, H. S. Chae. Prevalence and risk factors for reduced pulmonary function in diabetic patients: The Korea National Health and Nutrition Examination Survey. Korean J Intern Med, vol. 32, no. 4, pp. 682-689. 2017. 
[38] F. Innocenti, A. Fabbri, R. Anichini, S. Tuci, G. Pettina, F. Vannucci, L. A. De Giorgio, G. Seghieri. Indications of reduced pulmonary function in type 1 (insulin-dependent) diabetes mellitus. Diabetes Res Clin Pract, vol. 25, no. 3, pp. 161-168. 1994.

[39] T. Soulis, V. Thallas, S. Youssef, R. E. Gilbert, B. G. McWilliam, R. P. Murray-McIntosh, M. E. Cooper. Advanced glycation end products and their receptors co-localise in rat organs susceptible to diabetic microvascular injury. Diabetologia, vol. 40, no. 6, pp. 619-628. 1997.

[40] S. G. Keerthi, B. Sharan, M. Singh, H. K. Bandi, J. K. Preetham. Deterioration of Pulmonary Functions in Type 2 Diabetes Mellitus. Journal of Pharmacy and Biological Sciences, vol. 1, no. 1, pp. 39-43. 2012.

[41] C. K. Sreeja, E. Samuel, C. Kesavachandran, S. Shashidhar. Pulmonary function in patients with diabetes mellitus. Indian J Physiol Pharmacol, vol. 47, no. 1, pp. 87-93. 2003. 